\title{
Parametric Study of an Adsorption Refrigeration System Using Different Working Pairs
}

\author{
\{Mohamed G. Gado*, E. Elgendy, Khairy Elsayed ${ }^{\dagger}$, M. Fatouh $\}^{*}$
}

\begin{abstract}
Adsorption refrigeration system (ARS) is regarded as one of promising clean technologies since it uses a low-grade thermal energy (solar energy, waste heat, etc.). The present paper provides a dynamic modeling of two-bed ARS with RD silica gel/water and SWS-1L/water as working pairs based on MATLAB program. The refrigeration capacity and coefficient of performance are calculated in terms of cycle time, hot water inlet temperature, cooling water inlet temperature, and chilled water inlet temperature.

Simulation results indicated that the coefficient of performance increases linearly with adsorption/desorption time. Refrigeration capacity increases gradually until reaches an optimal adsorption/desorption time and then reduces. RD silica gel/water and SWS-1L/water pairs provides a refrigeration capacity of $11.7 \mathrm{~kW}$ and $4 \mathrm{~kW}$, respectively at evaporator temperature of $10^{\circ} \mathrm{C}$. Both working pairs are limited by the hot water inlet temperature of $95^{\circ} \mathrm{C}$. The half cycle times are fixed to 350 and $280 \mathrm{~s}$ for RD silica gel/water and SWS$1 \mathrm{~L} /$ water, respectively which selected based on optimum time which gives maximum cooling capacity, whereas the switching time for pre-cooling and pre-heating processes is set to $30 \mathrm{~s}$ for both working pairs.
\end{abstract}

Keywords: RD silica gel, SWS-1L, Water, Adsorption, Refrigeration system.

\section{Nomenclature}

$\begin{array}{ll}\mathrm{A} & \text { surface area, }\left(\mathrm{m}^{2}\right) \\ \mathrm{c}_{\mathrm{p}} & \text { specific heat capacity }(\mathrm{kJ} / \mathrm{kg} . \mathrm{K}) \\ \mathrm{D}_{\mathrm{so}} & \text { pre-exponential constant }\left(\mathrm{m}^{2} / \mathrm{s}\right) \\ \mathrm{E}_{\mathrm{a}} & \text { activation energy }(\mathrm{kJ} / \mathrm{kmol}) \\ \mathrm{e} & \text { evaporation } \\ \mathrm{h} & \text { specific enthalpy }(\mathrm{kJ} / \mathrm{kg}) \\ \mathrm{K}_{\mathrm{o}} & \text { pre-exponential constant }(1 / \mathrm{Pa}) \\ \mathrm{M} & \text { mass }(\mathrm{kg}) \\ \dot{\mathrm{m}} & \text { mass flow rate }(\mathrm{kg} / \mathrm{s}) \\ \mathrm{P} & \text { pressure }(\mathrm{kPa}) \\ \mathrm{H}_{\mathrm{st}} & \text { isosteric heat of adsorption }(\mathrm{kJ} / \mathrm{kg}) \\ \mathrm{Q} & \text { heat transfer rate } \\ \mathrm{q}^{*} & \text { adsorption equilibrium uptake }(\mathrm{kg} / \mathrm{kg}) \\ \mathrm{Q} & \text { instantaneous adsorption uptake }(\mathrm{kg} / \mathrm{kg})\end{array}$

Corresponding author, gaber.m-gado@m-eng.helwan.edu.eg

$†$ Vrije Universiteit Brussel, Department of Mechanical Engineering, Research Group Fluid Mechanics and Thermodynamics, Pleinlaa n 2, 1050 Brussels, Belgium.

¥ Mechanical Power Engineering Department, Faculty of Engineering, Helwan University, Masaken El-Helmia P.O., Cairo 11718, Egypt. 


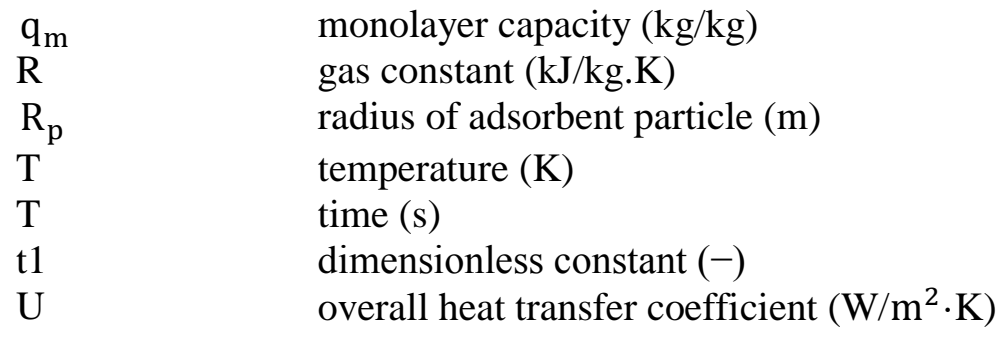

$\begin{array}{ll}\begin{array}{l}\text { Subscripts } \\ \text { ads } \\ \text { chw }\end{array} & \text { Adsorber } \\ \text { Cy } & \text { chilled water } \\ \text { con } & \text { Cycle } \\ \text { cw } & \text { condenser } \\ \text { des } & \text { Desoring water } \\ \text { eva } & \text { Evaporator } \\ \text { HX } & \text { heat exchanger } \\ \text { hw } & \text { hot water } \\ \text { In } & \text { Inlet } \\ \text { liq } & \text { Liquid } \\ \text { max } & \text { Maximum } \\ \text { min } & \text { Minimum } \\ \text { out } & \text { Outlet } \\ \text { sat } & \text { Saturation } \\ \text { Sg } & \text { silica gel } \\ \text { wv } & \text { water vapor }\end{array}$

Abbreviations

$\begin{array}{ll}\text { COP } & \text { coefficient of performance }(-) \\ \text { RD } & \text { type of silica gel desiccant material } \\ \text { SWS } & \text { selective water sorbent }\end{array}$

\section{Introduction}

Nowadays Egypt suffers from electricity crisis; a great share of Egyptian electricity consumption contributes to the domestic sector air conditioning systems with $32 \%$ of the electrical energy [1]. Therefore, an increasing attention has been paid to the development of alternative air-conditioning systems. Many promising technologies have been used recently in refrigeration systems. Solar assisted cooling system has become one of these promising air conditioning technologies, and it has an advantage in hot areas due to the near synchronizing of peak cooling load with the available solar energy and that is more suitable for the climatic conditions of Egypt. Solar-assisted cooling systems are classified into several types of solar thermal cooling systems such as ejector refrigeration, desiccant, absorption and adsorption refrigeration systems.

Solar adsorption refrigeration has many advantages over other refrigeration systems such as lowering generation temperature (e.g. $55-90^{\circ} \mathrm{C}$ ), as compared to the temperature $\left(90-120^{\circ} \mathrm{C}\right.$ ) for absorption refrigeration systems, no crystallization problem, less corrosion problems, operation simplicity and environmentally friendly working fluids [2]. Therefore, the solar adsorption cooling system seems technologically possible and socially feasible in such areas where there is abundant solar energy. 
Many working pairs have been used in adsorption refrigeration systems. The silica gel water pair is well suited over a wide temperature range. Saha et al. [3] and Chua et al. [4] investigated adsorption refrigeration cycle using the silica gel water pair, which can be driven by hot water inlet temperature of $85^{\circ} \mathrm{C}$ with cooling water inlet temperature of $30^{\circ} \mathrm{C}$. New sorption material called Selective Water Sorbents (SWSs), which are the porous matrix impregnated with salt, were recently developed, and the thermodynamic performance of SWSs for heat pump applications was presented by Aristov et al. [5] and Restuccia et al. [6]. Among SWSs, SWS-1L (mesoporous silica gel impregnated with $\mathrm{CaCl}_{2}$ - showed favorable properties for low-grade heat driven heat pumps, such as a high water sorption capacity and low regeneration temperature.

Miyazaki et al. [7] investigated the improvement in the refrigeration capacity of two-bed adsorption chiller with RD type silica gel-water pair and with $\mathrm{CaCl}_{2}$-in-silica gel-water pair by the new cycle time allocation. Simulation results showed that the new cycle time was effective for both working pairs, and the cooling capacity was increased as much as by $6 \%$. El-Sharkawy et al. [8] presented a theoretical investigation of the effect of adsorption/desorption time allocation on the performance of adsorption chillers. Theoretical results showed that for a half cycle time of $350 \mathrm{~s}$, switching time of 35 s. Optimum adsorption/desorption time minimizes fluctuations in chilled water outlet temperature. It is found that the system COP increases with the increase of adsorption/desorption time and the effect of switching time is marginal. Moreover, numerous types of working pairs can be applied in various applications as reviewed by Goyal et al. [9] besides Bataineh and Taamneh [10].

The literature review revealed that the performance of adsorption refrigeration system is evaluated at half cycle time of $420 \mathrm{~s}$. However, there are a limited number of studies deals with the performance of adsorption refrigeration systems under the operation of the optimum cycle time. Therefore, the present work aims; firstly, to optimize adsorption/desorption time in order to enhance the performance of adsorption refrigeration system secondly, to simulate the system performance using different working pairs.

\section{Description of the Adsorption Refrigeration System}

The adsorption refrigeration system consists of four main components namely; an adsorber, a desorber, an evaporator, and condenser. The desorber is driven by using a hot water supply source. The desorber and adsorber are packed with desiccant material, which has the capability of adsorbing or desorbing the refrigerant during the adsorption or desorption process. Various valves are used to control the refrigerant flow rates as shown in Fig. 1.

Adsorption is an exothermic process, so the heat of adsorption needs to be removed by using a cooling water flow rate. On the other hand, heat (via hot water flow rate) is required to release the refrigerant from the adsorbent pores during the desorption process. The desorber and adsorber beds are controlled to work sequentially through four processes as shown in Fig. 2 namely; isosteric heating (preheating switching, $1 \rightarrow 2$ ), isobaric desorption/condensation $(2 \rightarrow 3)$, isosteric cooling (precooling switching, $3 \rightarrow 4$ ), and isobaric adsorption/evaporation $(4 \rightarrow 1)$. In the isosteric heating/cooling, the refrigerant amount in the beds remains constant. The following valves V1, V2, V3, and V4 are closed to keep the amount of refrigerant in the beds constant during preheating/precooling process as given in Fig. 2. As a result, during the preheating process the bed pressure increases from the evaporation pressure to the condensation pressure and vice versa during the precooling process. During the isobaric cooling process, one of the beds is connected to the evaporator to suck the refrigerant vapor 
from the evaporator producing the cooling effect. During the isobaric heating process, the other bed is connected to the condenser to deliver the refrigerant to be condensed and then to evaporator through the liquid line. Using two adsorption beds is necessary to obtain continuous cooling by making both of them work in parallel, while one bed in adsorption process and the other bed in desorption process [11].

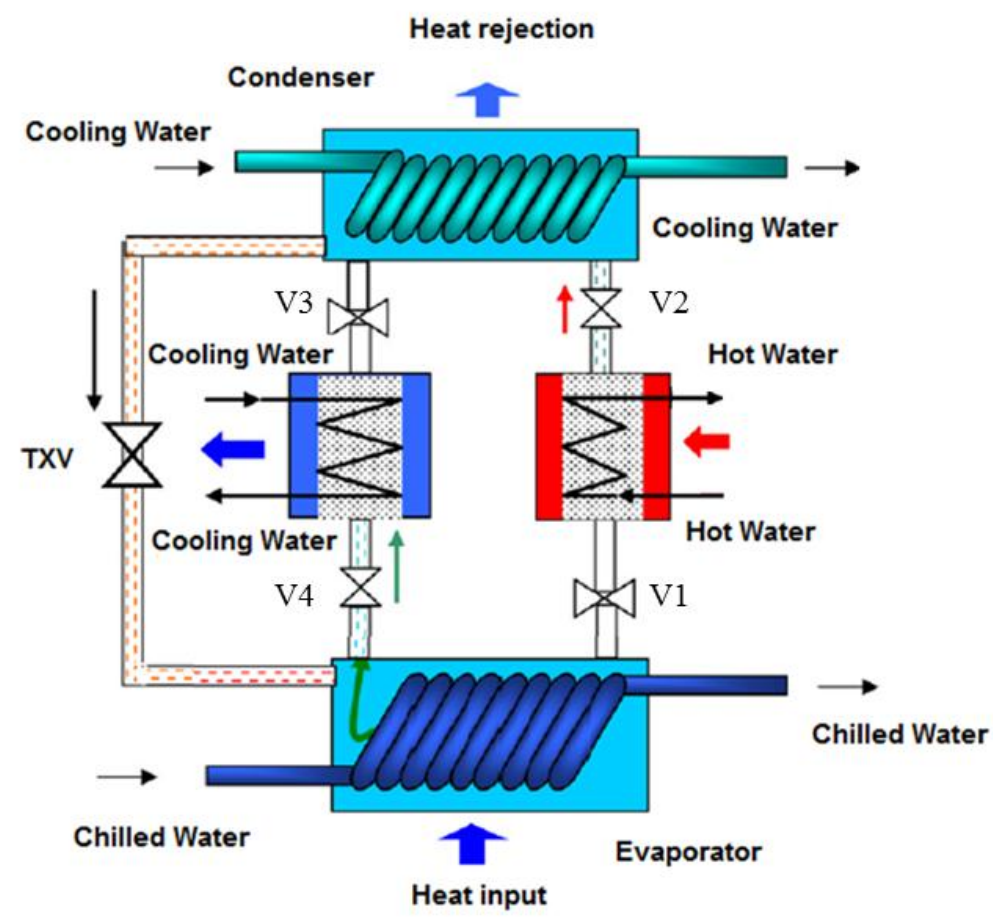

Fig. 1 Schematic diagram of an adsorption refrigeration system.

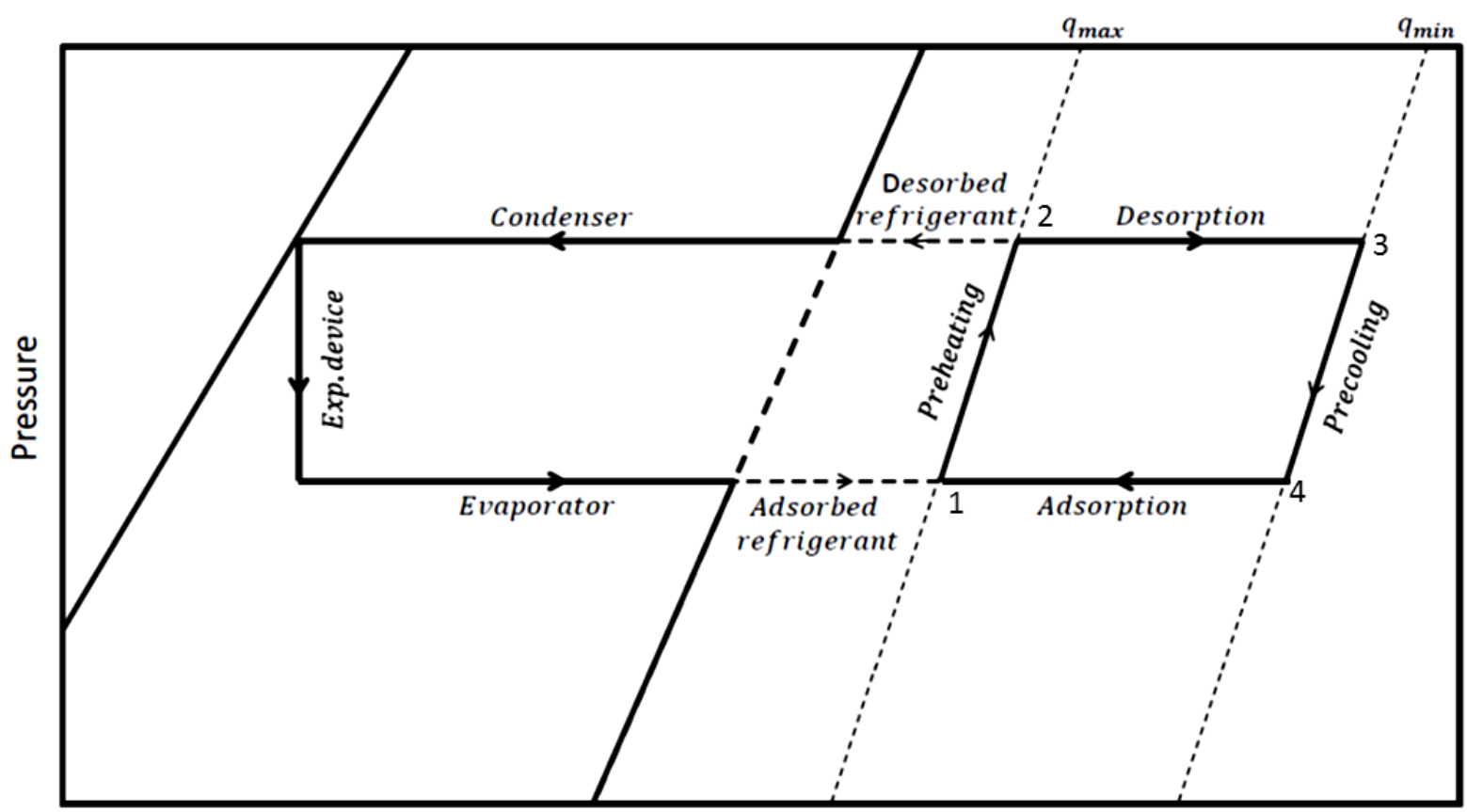

Enthalpy

Fig. 2 Pressure - enthalpy diagram of ideal adsorption refrigeration cycle. 


\section{Mathematical Modeling}

The adsorption refrigeration system using working pair of RD silica gel-water and SWS$1 \mathrm{~L} /$ water can be used to produces a cooling effect in the evaporator and rejects heat at the condenser. These phenomena are expressed mathematically using the mass and energy balances around major components of the adsorption refrigeration system [12].

\subsection{Rate of Adsorption and Desorption in Beds}

The rate of adsorption or desorption is governed by the linear driving force (LDF) kinetic equation [13]:

$\frac{d q}{d t}=\frac{15 D_{s o} e^{-E_{a} /(R T)}}{R_{p}^{2}}\left(q^{*}-q\right)$

where, $q^{*}$ is the amount of refrigerant at the equilibrium condition, $\mathrm{q}$ is the instantaneous water vapor uptake, $D_{s o}$ is the pre-exponential constant, $R_{p}$ is the silica gel particle radius, $\mathrm{R}$ the gas constant, and $\mathrm{T}$ is the temperature.

\subsection{Adsorption Isotherms}

The experimentally measured adsorption isotherm data of silica gel-water pair is fitted with Dubinin- Astakhov adsorption isotherm equation. The isotherm equation is given by,

$q^{*}=q_{o}\left(\frac{P_{s a t}}{P}\right)^{1 / 1.6}$

where, $\mathrm{q}_{\mathrm{o}}=0.346$ for silica-gel water and denotes the limiting amount of adsorbate uptake, $\mathrm{P}$ is pressure, and $P_{s a t}$ is the saturation pressure [3]. The Tóth equation is used to predict the adsorption equilibrium of the $\mathrm{CaCl}_{2}$-in-silica gel/water pair [15]:

$q^{*}=\frac{q_{m} K_{o} \cdot e^{\frac{H_{s t}}{R \cdot T}} \cdot P}{\left[1+\left(e^{\frac{H_{s t}}{R \cdot T}} \cdot P\right)^{t 1}\right]^{1 / t 1}}$

where, $H_{s t}$ is the isosteric heat of adsorption, $K_{o}$ is the pre-exponential constant, $\mathrm{t} 1$ is the dimensionless constant, and $q_{m}$ is the monolayer capacity.

\subsection{Energy Equation for the Adsorber Bed}

The adsorption process results in the liberation of heat of adsorption at the adsorber, providing a useful heat energy output and a cooling effect in the evaporator. As the evaporated refrigerant is associated onto the solid adsorbent by the flow of cooling fluid at ambient conditions during adsorption period, heat energy is transferred from cooling water to the adsorber. The energy balance equation of the adsorber bed connected with the evaporator is given by [13-14],

$$
\begin{aligned}
\left(\left(M_{s g} c_{p, s g}\right)+\right. & \left.\left(M_{H X} c_{p, H X}\right)+\left(M_{s g} c_{p, w v} q\right)\right) \frac{d T_{a d s}}{d t} \\
& =M_{s g} H_{s t} \frac{d q_{a d s}}{d t}+\dot{m}_{c w} c_{p, c w}\left(T_{c w, \text { in }}-T_{c w, o u t}\right)
\end{aligned}
$$

where, $T_{c w, o u t}$ is the outlet water temperature of the adsorber bed, $T_{c w, i n}$ is the inlet water temperature of the adsorber bed, $T_{a d s}$ is the adsorber bed temperature, $\dot{m}_{c w}$ is the mass flow 
rate of the cooling water, $M_{s g}$ is the packed mass of silica gel, $M_{H X}$ is the mass of the bed, $\frac{d q_{a d s}}{d t}$ is the uptake rate of the adsorber, $\mathrm{q}$ is the instantaneous uptake, $c_{p, s}$ is the specific heat of silica gel, $c_{p, H X}$ is the specific heat of heat the bed, $c_{p, w v}$ is the specific heat of the adsorbed phase, and $c_{p, c w}$ is the specific heat of the adsorbed phase. The outlet temperature of the water from heat exchanger is expressed as [14]:

$T_{c w, \text { out }}=T_{a d s}+\left(T_{c w, \text { in }}-T_{a d s}\right) \exp \left(\frac{-U_{a d s} A_{a d s}}{\dot{m}_{c w} c_{p, c w}}\right)$

where, $U_{a d s}$ is the overall heat transfer coefficient of the bed, $A_{a d s}$ is the surface area of the bed.

\subsection{Energy Equation for the Desorber Bed}

Desorption process results in the adding a heat of adsorption at the desorber, providing a useful heat energy output and a heating effect in the condenser. As the desorbed bed is heated by an external heat source and the adsorbed water vapor is desorbed from the adsorbent and then condensed in the water-cooled condenser. The desorbed water vapor is dissociated from the solid adsorbent by the flow of heating fluid during desorption period, heat energy is transferred from hot water to the desorber. The energy balance equation of the desorber bed connected with the condenser is given by [13-14],

$$
\begin{aligned}
\left(\left(M_{s g} c_{p, s g}\right)+\right. & \left.\left(M_{H X} c_{p, H X}\right)+\left(M_{s g} c_{p, w v} q\right)\right) \frac{d T_{d e s}}{d t} \\
& =M_{s g} H_{s t} \frac{d q_{d e s}}{d t}+\dot{m}_{h w} c_{h w}\left(T_{h w, \text { in }}-T_{h w, o u t}\right)
\end{aligned}
$$

where, $T_{h w \text {, out }}$ is the outlet water temperature of the desorber bed, and $\frac{d q_{d e s}}{d t}$ is the uptake rate of the desorber. The outlet temperature of the water from heat exchanger is expressed as [14]:

$T_{h w, o u t}=T_{d e s}+\left(T_{h w, i n}-T_{d e s}\right) \exp \left(\frac{-U_{d e s} A_{d e s}}{\dot{m}_{h w} c_{h w}}\right)$

where, $U_{d e s}$ is the overall heat transfer coefficient of the bed, $A_{d e s}$ is the surface area of the bed.

\subsection{Energy Equation for the Evaporator}

The energy balance for the evaporator is expressed as [13-14]:

$$
\begin{aligned}
\left(\left(M_{w, e v a} c_{w}\right)+\right. & \left.\left(M_{H X} c_{p, H X}\right)\right) \frac{d T_{\text {eva }}}{d t} \\
& =M_{s g} h_{f g} \frac{d q_{a d s}}{d t}+\dot{m}_{c h w} c_{c h w}\left(T_{c h w, \text { in }}-T_{c h w, o u t}\right)
\end{aligned}
$$

where, $T_{c h w, o u t}$ is the outlet water temperature of the chilled water tank and $h_{f g}$ and $c_{c h w}$ are the heat of vaporization and the specific heat of the chilled water, respectively. The outlet temperature of the water from heat exchanger is estimated as [14]:

$T_{c h w, o u t}=T_{\text {eva }}+\left(T_{c h w, i n}-T_{\text {eva }}\right) \exp \left(\frac{-U_{\text {eva }} A_{\text {eva }}}{\dot{m}_{c h w} c_{c h w}}\right)$

where, $U_{\text {eva }}$ is the overall heat transfer coefficient of the evaporator, $A_{\text {eva }}$ is the surface area of the evaporator. 


\subsection{Energy Equation for the Condenser}

In desorption process, the desorbed refrigerant is delivered to the condenser as latent heat, and this amount of heat is pumped to the environment by the flow of external cooling water. The condenser energy balance equation can be expressed as [13-14]:

$$
\begin{gathered}
\left(\left(M_{w, \text { con }} c_{w}\right)+\left(M_{H X} c_{p, H X}\right)\right) \frac{d T_{c o n}}{d t} \\
=M_{s g} h_{f g} \frac{d q_{d e s}}{d t}+\dot{m}_{c h w w} c_{c h w}\left(T_{c h w, i n}-T_{c h w, o u t}\right) \\
\quad-M_{s g} c_{p, s g}\left(T_{d e s}-T_{c o n}\right) \frac{d q_{d e s}}{d t}
\end{gathered}
$$

where, $T_{c w, o u t}$ is the outlet water temperature of the cooling water tank and $c_{c w}$ is the specific heat of the cooling water, respectively. The outlet temperature of the water from heat exchanger can be written as [14]:

$T_{c w, o u t}=T_{c o n}+\left(T_{c w, i n}-T_{c o n}\right) \exp \left(\frac{-U_{c o n} A_{c o n}}{\dot{m}_{c w} c_{c w}}\right)$

where, $U_{c o n}$ is the overall heat transfer coefficient of the condenser, $A_{c o n}$ is the surface area of the condenser.

\subsection{Mass Balance}

The change of the liquid refrigerant mass flow rate (due to adsorption and desorption process) can be expressed through the following equation [13-14]:

$\frac{d M_{w, e v a}}{d t}=-M_{s g}\left(\frac{d q_{a d s}}{d t}+\frac{d q_{d e s}}{d t}\right)$

where, $M_{w, e v a}$ is the refrigerant water vapor mass.

\subsection{System Performance}

Adsorption refrigeration system performance is defined by its refrigeration capacity COP. The two parameters are the most important data among the technical specifications of such products. Refrigeration capacity and COP are expressed by [14],

$Q_{e}=\frac{\int_{0}^{t_{c y}} \dot{m}_{c h} c_{p, c h w}\left(T_{c h w, i n}-T_{c h w, o u t}\right) d t}{t_{c y}}$

$C O P=\frac{\int_{0}^{t_{c y}} \dot{m}_{c h} c_{p, c h w}\left(T_{c h w, \text { in }}-T_{c h w, o u t}\right) d t}{\int_{0}^{t_{c y}} \dot{m}_{h w} c_{p, h w}\left(T_{h w, \text { in }}-T_{h w, o u t}\right) d t}$

System performance is calculated for one complete cycle time that is the sum of adsorption time, pre-heating time, desorption time, and pre-cooling time.

\section{Computational Procedure}

The simulation procedure starts with the initialization of (i) operating constants (isotherm equation constants, kinetics constants and components' geometry), (ii) operating variables (hot, cooling and chilled water inlet temperatures and adsorption/desorption cycle times), and 
(iii) estimated ( $T_{a d s}, T_{\text {des }}, T_{\text {eva }}, T_{\text {con }}, q_{a d s}, q_{\text {des }}$ ), the initial values of differential equation parameters. The system design constants and kinetics constants used in the present simulation are summarized in Table 1. The simulation of the system transient response is carried out using version R2012b of MATLAB [16] linked to version 8 of REFPROP [17]. The built-in function ODE45 is used for solving ordinary differential equations [18].

Table 1 - Operating constants of the adsorption refrigeration system [7].

\begin{tabular}{|l|l|}
\hline Parameter & \multicolumn{1}{|c|}{ Value } \\
\hline $\mathrm{D}_{\mathrm{so}}$ & $2.54 \times 10^{-4}\left(\mathrm{~m}^{2} / \mathrm{s}\right)$ for SWS-1L and RD silica gel \\
\hline $\mathrm{E}_{\mathrm{a}}$ & $4.2 \times 10^{4}(\mathrm{~J} / \mathrm{mole})$ for SWS-1L and RD silica gel \\
\hline $\mathrm{R}_{\mathrm{p}}$ & $1.7 \times 10^{-4} \mathrm{~m}$ for type RD and $1.74 \times 10^{-4} \mathrm{~m}$ for SWS-1L \\
\hline$M_{s g}$ & $47 \mathrm{~kg}$ for type RD and $20 \mathrm{~kg}$ for SWS-1L \\
\hline$\left(\dot{\mathrm{m}} c_{p}\right)_{a d s / \text { des }}$ & $\begin{array}{l}\text { Heating: } 1.3 \times 4.186 \mathrm{~kW} / \mathrm{K} \text { for RD silica gel and } 1.3 \times 4.186 \mathrm{~kW} / \mathrm{K} \text { for SWS-1L } \\
\text { Cooling: } 1.3 \times 4.186 \mathrm{~kW} / \mathrm{K} \text { for RD silica gel and } 1.3 \times 4.186 \mathrm{~kW} / \mathrm{K} \text { for SWS-1L }\end{array}$ \\
\hline$\left(\dot{\mathrm{m}} c_{p}\right)_{c w}$ & $1.3 \times 4.186 \mathrm{~kW} / \mathrm{K}$ for SWS-1L and RD silica gel \\
\hline$\left(\dot{\mathrm{m}} c_{p}\right)_{c h w}$ & $0.71 \times 4.186 \mathrm{~kW} / \mathrm{K}$ for SWS-1L and RD silica gel \\
\hline$\left(\mathrm{M} c_{p}\right)_{H X}$ & $(64.04 \times 0.386+51.20 \times 0.905) \mathrm{kJ} / \mathrm{K}$ for RD silica gel and half of mass for SWS-1L \\
\hline$\left(\mathrm{M} c_{p}\right)_{c o n}$ & $(24.28 \times 0.386+20 \times 4.186) \mathrm{kJ} / \mathrm{K}$ for SWS-1L and RD silica gel \\
\hline$\left(\mathrm{M} c_{p}\right)_{e v a}$ & $(12.45 \times 0.386+50 \times 4.186) \mathrm{kJ} / \mathrm{K}$ for SWS-1L and RD silica gel \\
\hline$(\mathrm{U} A)_{H X}$ & $\begin{array}{l}(1724.14 \times 2.46) \mathrm{W} / \mathrm{K} \text { for RD silica gel } \\
(1500 \times 1.23) \mathrm{W} / \mathrm{K} \text { during desorption for SWS-1L } \\
(1400 \times 1.23) \mathrm{W} / \mathrm{K} \text { during adsorption for SWS-1L }\end{array}$ \\
\hline$(\mathrm{U} A)_{c o n}$ & $(4115.23 \times 3.73) \mathrm{W} / \mathrm{K}$ for SWS-1L and RD silica gel \\
\hline$(\mathrm{U} A)_{e v a}$ & $(2557.54 \times 1.91) \mathrm{W} / \mathrm{K}$ for SWS-1L and RD silica gel \\
\hline
\end{tabular}

\section{Results and Discussions}

Simulation of the adsorption refrigeration system performance was analyzed by employing the proposed mathematical model under a wide range of cycle time $(0: 900 \mathrm{~s})$, and the hot, cooling, and chilled water inlet temperatures of 85,30 and $14{ }^{\circ} \mathrm{C}$, respectively. A good agreement between the experimental of Chua et al. [4] and the present simulation validates the numerical model for the temperature profile of the major component of the system at the adsorption/desorption time as illustrated in Table 2.

Table 2 - Comparison between simulated and experimental outsource temperature profiles.

\begin{tabular}{clllllllc}
\hline Time & \multicolumn{2}{l}{ Adsorber $\left({ }^{\circ} \mathrm{C}\right)$} & \multicolumn{2}{c}{ Desorber $\left({ }^{\circ} \mathrm{C}\right)$} & \multicolumn{2}{c}{ Condenser $\left({ }^{\circ} \mathrm{C}\right)$} & \multicolumn{2}{c}{ Evaporator $\left({ }^{\circ} \mathrm{C}\right)$} \\
$(\mathrm{s})$ & Exp. & Sim. & Exp. & Sim. & Exp. & Sim. & Exp. & Sim. \\
\hline 100 & 36.803 & 36.870 & 76.781 & 78.157 & 35.849 & 36.248 & 10.077 & 11.098 \\
200 & 34.961 & 34.139 & 80.842 & 80.932 & 35.493 & 34.561 & 10.899 & 10.210 \\
300 & 34.073 & 33.740 & 83.706 & 83.085 & 32.785 & 33.340 & 11.498 & 10.543 \\
400 & 33.473 & 33.207 & 84.839 & 84.705 & 31.498 & 32.519 & 11.698 & 11.098 \\
\hline
\end{tabular}

\subsection{Effect of Adsorption /Desorption Time}

Effect of adsorption/desorption time on refrigeration capacity $\left(Q_{e}\right)$ and COP is shown in Figs. 3 and 4 for Silica gel/water pair and SWS - 1L/water pair, respectively. It is found for silica gel/water pair that the highest $Q_{e}$ values were obtained when adsorption/desorption time lies between 300 and 350 seconds. However, the highest $Q_{e}$ values for SWS - 1L/water pair were 
obtained in the range of 200 and 300 seconds. The refrigeration capacity increases as the adsorption/desorption time increases. This is due to the increase in the adsorbed refrigerant with the adsorption/desorption time until reaches the optimum time. As the adsorption/desorption time is greater than the optimum time there are a less intensive adsorption/desorption process, so the $Q_{e}$ decreases abruptly. The COP increases uniformly as the adsorption/desorption time increases, because of low consumption of hot water heat with cycle time.

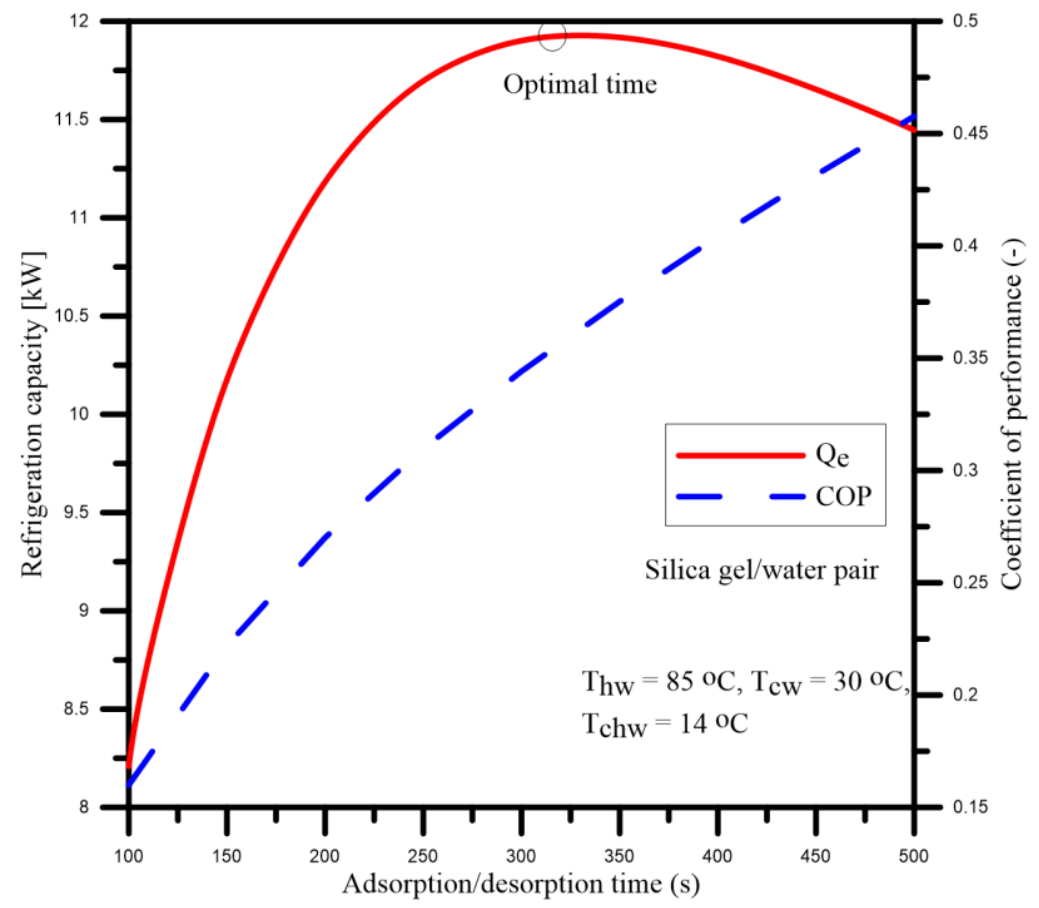

Fig. 3 RD Silica gel/water pair adsorption/desorption time effect on $Q_{e}$ and COP.

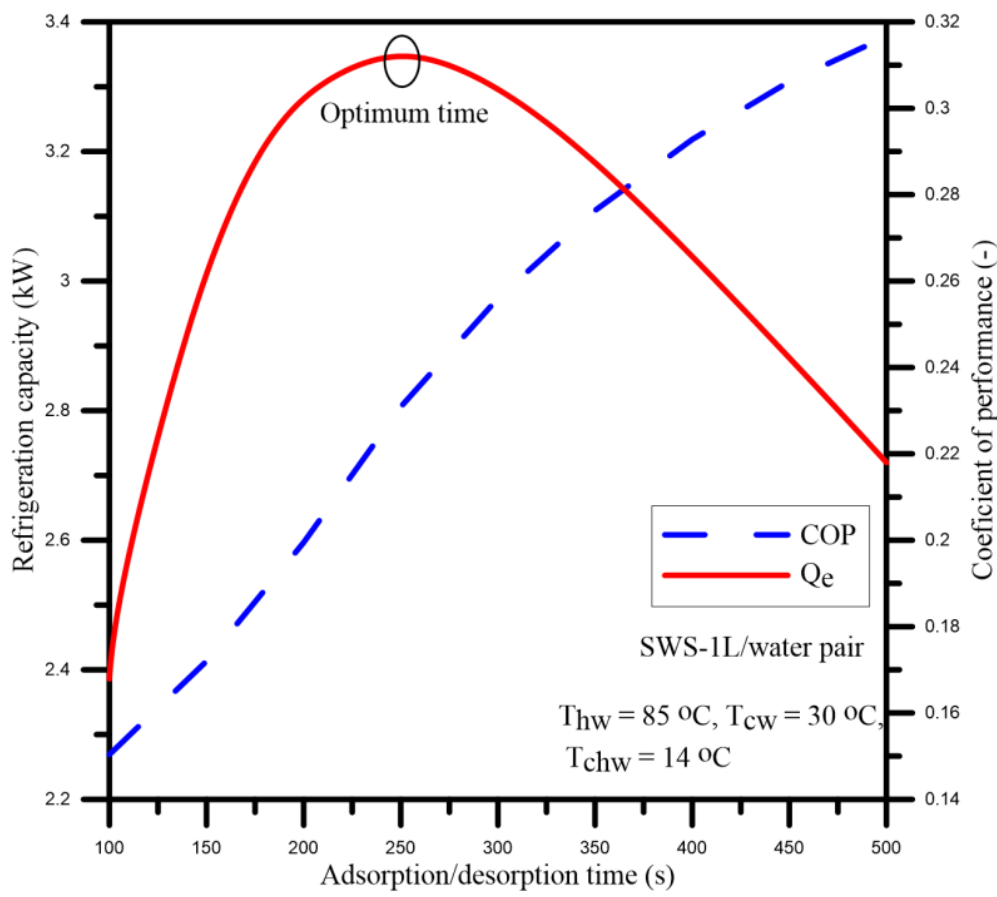

Fig. 4 SWS - 1L/Water pair adsorption/desorption cycle time effect on $Q_{e}$ and COP. 


\subsection{Temperature Profile of Two Bed Adsorption Refrigeration System}

Influence of the cycle time on temperature profile of the two-bed adsorption refrigeration system can be predicted from Fig. 5. It can be noted that the hot, cooling and chilled water inlet temperatures are kept constant at 85,30 and $14{ }^{\circ} \mathrm{C}$, respectively. The half cycle times are fixed to 350 and $280 \mathrm{~s}$ for RD silica gel/water and SWS-1L/water, respectively which selected based on optimum time at which the maximum cooling capacity is achieved (as shown in Figs. 3 and 4). The switching time for pre-cooling and pre-heating processes is set automatically to the time at which the pressure in the heated bed becomes equal to the condenser pressure. It sets to $30 \mathrm{~s}$ for RD silica gel/water and SWS-1L/water working pairs. Temperature profiles for adsorber/desorber bed, evaporator, and condenser is presented with the cycle time for RD silica gel/water (solid lines) and SWS-1L/water (dash lines) working pairs. It is seen that, desorber/desorber bed temperature varies from 34 to $80{ }^{\circ} \mathrm{C}$ for both working pairs while the evaporator temperature fluctuates around 8 and $12{ }^{\circ} \mathrm{C}$ for $\mathrm{RD}$ silica gel/water and SWS-1L/water working pairs, respectively. It can be observed that the silica $\mathrm{gel} /$ water pair is lower than that of the SWS-1L/water pair.

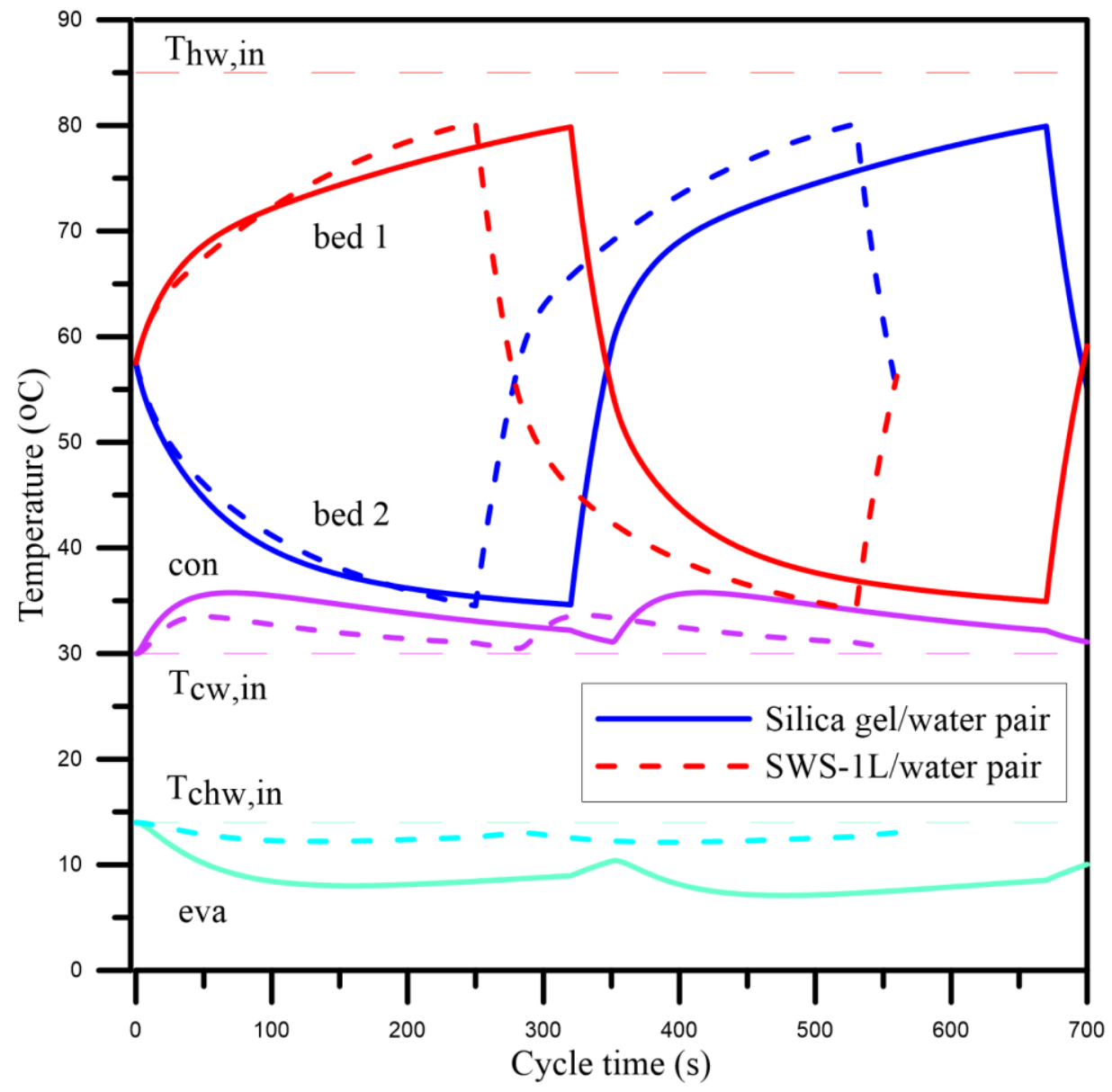

Fig. 5 Temperature history of the adsorber, desorber, evaporator, and condenser of the adsorption refrigeration system. 


\subsection{Effect of Chilled Water Outlet Temperature}

The chilled water outlet temperature profile for one full cycle time is shown in Fig. 6. It is observed that the RD silica gel/water reaches a lower temperature of $8.5^{\circ} \mathrm{C}$, while the SWS-1L/water reaches a chilled water of $12.5^{\circ} \mathrm{C}$. It is observed that the fluctuations of the chilled water outlet temperature are significantly reduced by using SWS-1L/water working pair.

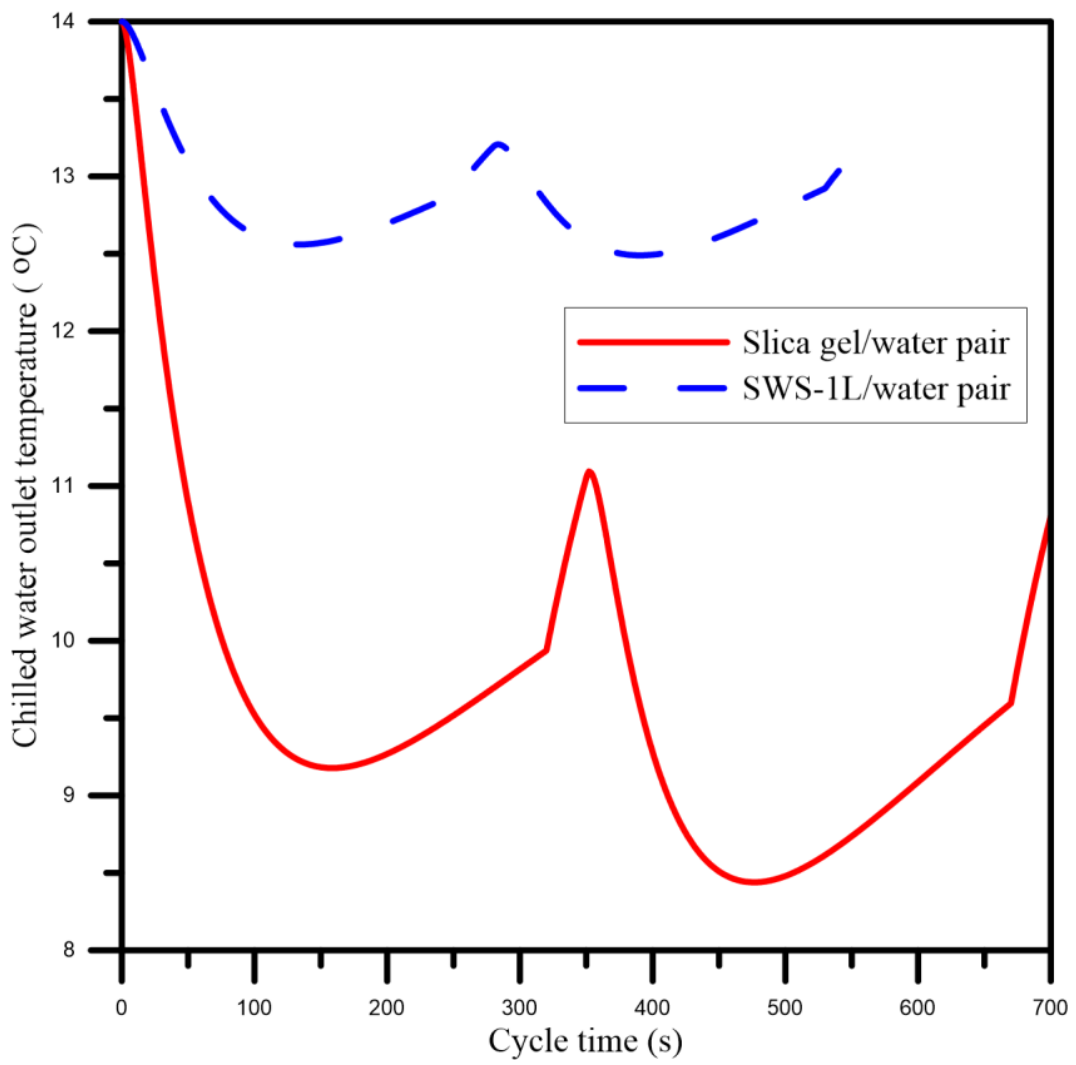

Fig. 6 Chilled water outlet temperature profiles for both working pairs.

\subsection{Effect of Hot Water Inlet Temperature}

The effects of regeneration temperature on refrigeration capacity and COP with fixed cooling water, chilled inlet temperatures, half cycle time and heat transfer fluid flow rates are taken as the rated values which are shown in Table 1 for silica gel/water working pair. It can be seen from Fig. 7 that the refrigeration capacity increases gradually from 6 to $16 \mathrm{~kW}$ as the heat source temperatures varies from 55 to $95^{\circ} \mathrm{C}$. This is due to the increase in the amount of refrigerant being desorbed at higher hot water inlet temperatures. However, the simulated COP increases sharply for hot water inlet temperatures up to $80{ }^{\circ} \mathrm{C}$, and shows a small increase for relatively higher heat source temperatures. This means that the heat consumed to desorb the refrigerant from the desiccant material becomes relatively higher than the cooling effect generated.

Fig. 8 indicates the effects of regeneration temperature on refrigeration capacity and COP with fixed cooling water, chilled inlet temperatures, half cycle time and heat transfer fluid flow rates are taken as the rated values which are shown in Table 1 for SWS-1L/water working pair. The system achieves refrigeration capacity of $4 \mathrm{~kW}$ at driving heat source temperature of $95^{\circ} \mathrm{C}$ which can be obtained from waste heat or solar energy. 


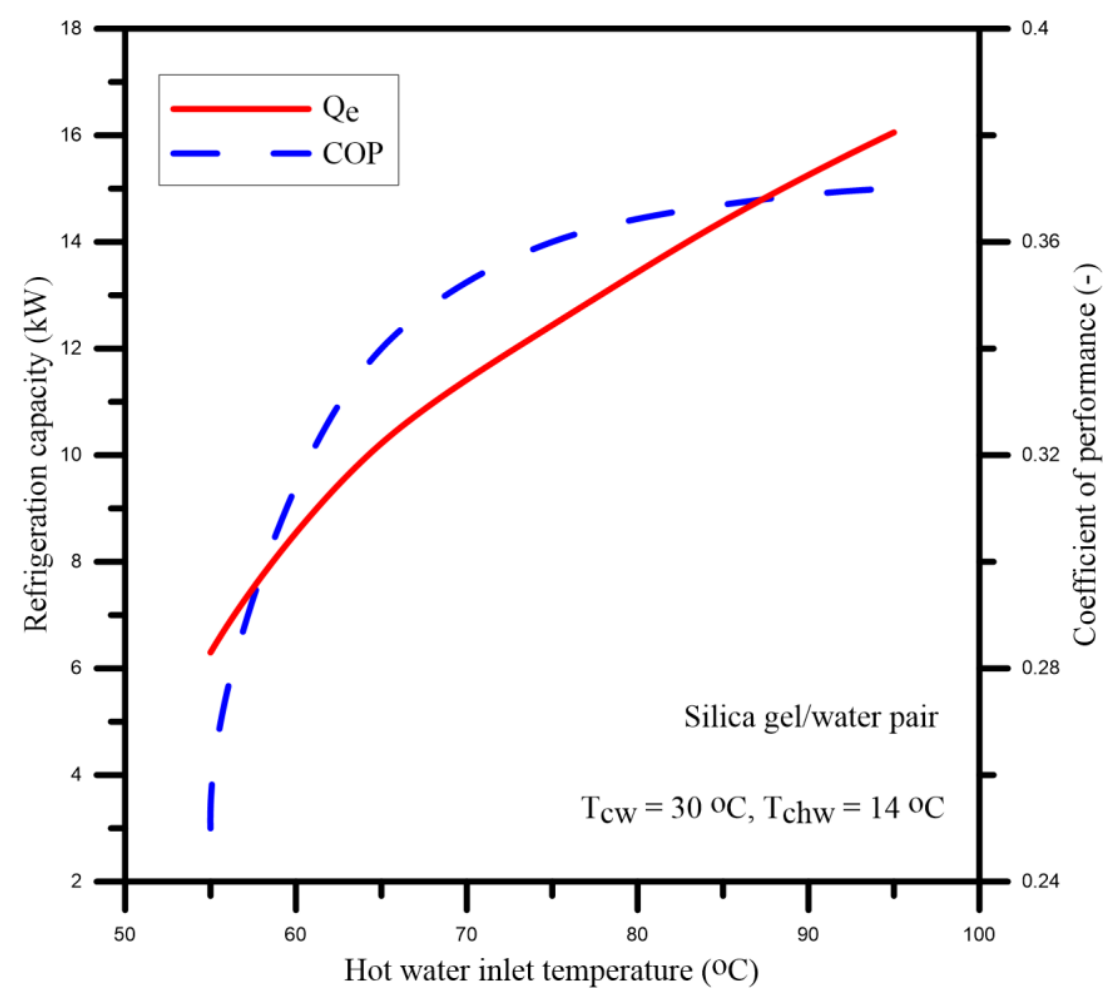

Fig. 7 Hot water inlet temperature effects on refrigeration capacity and COP of Silica gel/water adsorption cooling cycle.

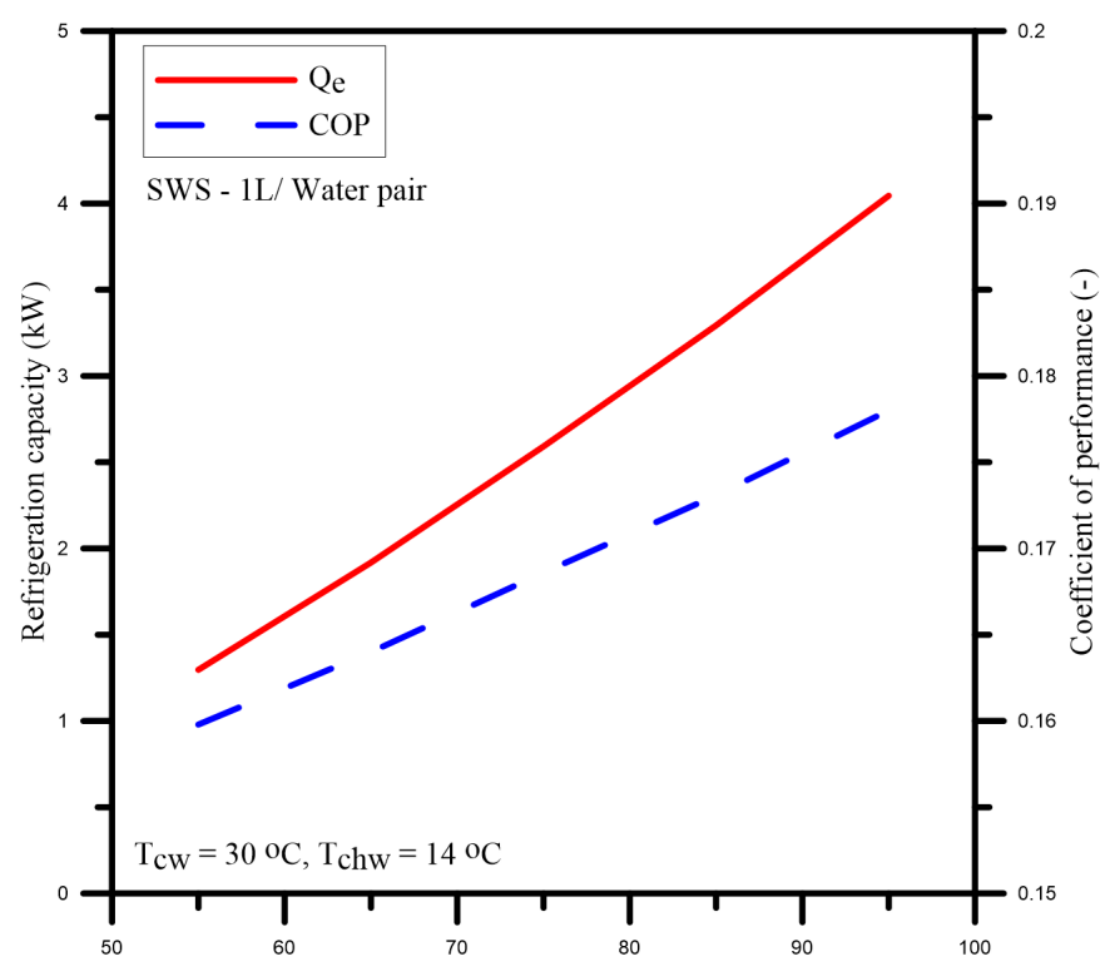

Hot water inlet temperature $\left({ }^{\circ} \mathrm{C}\right)$

Fig. 8 Hot water inlet temperature effects on refrigeration capacity and COP of SWS - 1L/water adsorption cooling cycle. 


\subsection{Effect of Cooling Water Inlet Temperature}

Variation of both refrigeration capacity and COP with cooling water inlet temperature is illustrated in Fig. 9. Obviously, both refrigeration capacity and COP decrease linearly with the increase of cooling water inlet temperature. This is due to, the decrease in the amount of refrigerant adsorbed in the RD silica gel with higher coolant temperatures. As the cooling water inlet temperature increases from 25 to $40{ }^{\circ} \mathrm{C}$, the refrigeration capacity and COP decreases by $21.7 \%$ and $7.8 \%$, respectively.

\subsection{Effect of Chilled Water Inlet Temperature}

Influence of chilled water inlet temperature on refrigeration capacity and COP for RD silica gel/water adsorption refrigeration system as shown in Fig. 10. Clearly, as the chilled water inlet temperature increases, the refrigeration capacity and COP decreases. This due to, the increase in amount of refrigerant being adsorbed in the desiccant material pores. When the chilled water inlet temperature changed from 10 to $22^{\circ} \mathrm{C}$ refrigeration capacity and COP increases by $24.3 \%$ and $26 \%$, respectively.

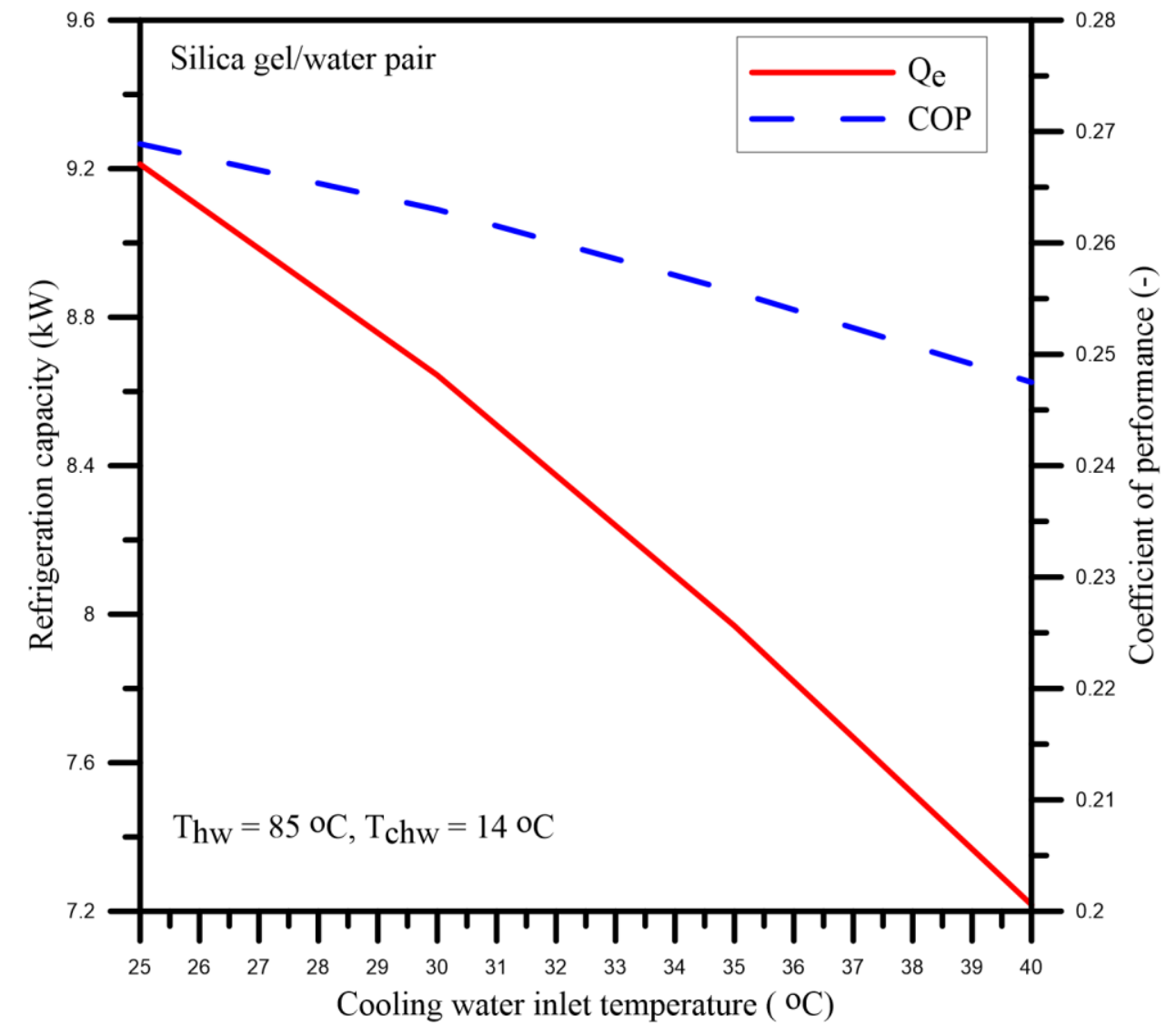

Fig. 9 Cooling water inlet temperature effects on refrigeration capacity and $C O P$. 


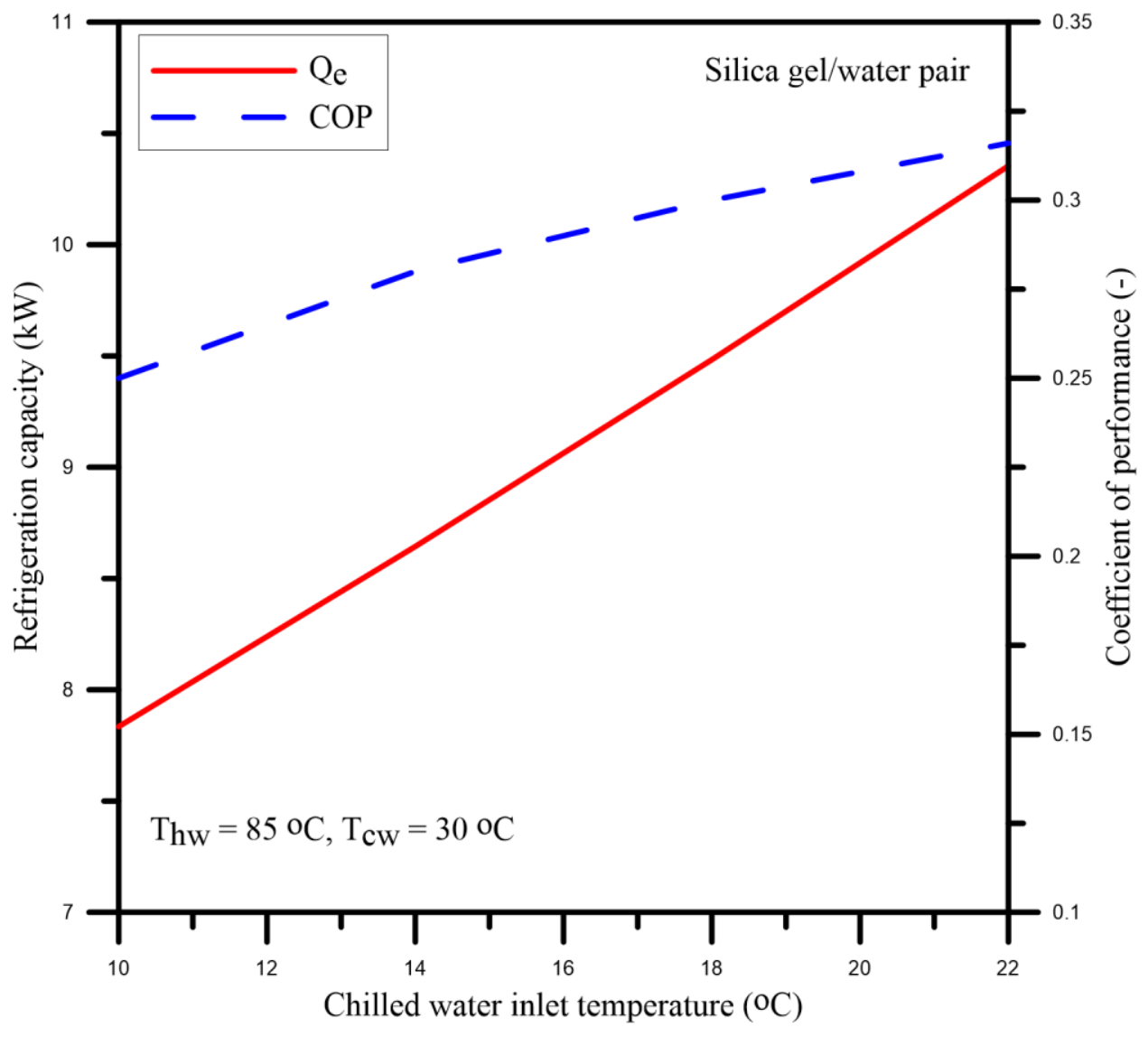

Fig. 10 Chilled water inlet temperature effects on refrigeration capacity and $\mathrm{COP}$.

\section{Conclusions}

Performance characteristics of a two - bed adsorption refrigeration system using silica gel/water and SWS-1L/water as working pairs are simulated and reported. The half cycle time is fixed to 350 and $280 \mathrm{~s}$ for Silica gel/water and SWS-1L/water, respectively based on an optimization procedure. The optimization procedure is used to estimate the optimal value of adsorption/desorption time that maximize the cooling refrigeration for both working pairs. The reported results can be summarized as:

- The system COP increases as the adsorption/desorption time increases.

- The cooling capacity reaches its maxima value at half cycle time of 320 and $250 \mathrm{~s}$ for RD silica gel/water and SWS-1L/water, respectively.

- Silica gel/water and SWS-1L/water pair provides a refrigeration capacity of 11.7 $\mathrm{kW}$ and $4 \mathrm{~kW}$, respectively.

- The fluctuations of the chilled water outlet temperature are significantly reduced by using SWS-1L/water working pair. 


\section{References}

[1] El-Sharkawy I.I., AbdelMeguid H., Saha B.B., "Potential application of solar powered adsorption cooling systems in the Middle East", Appl Energy 2014;126:235-45.

[2] Wang R., Adsorption refrigeration technology: Theory and application, $1^{\text {st }}$. ed., Vol. 1 , Wiley, Singapore, 2014, pp. 2-3.

[3] Saha B.B., Boelman E.C., Kashiwagi T., "Computational analysis of an advanced adsorption refrigeration cycle”, Energy 1995;983:994-20.

[4] Chua H.T., Ng K.C., Malek A., Kashiwagi T., Akisawa A., Saha B.B., "Modeling the performance of two-bed silica gel water adsorption chillers", Int J Refrig 1999; 194:204-22.

[5] Aristov, Y.I., Restuccia, Cacciola, G., Parmon, V.N., "A family of new working materials for solid sorption air conditioning systems", Appl Therm Eng 2002; 191:20422.

[6] Restuccia, G., Freni, A., Vasta, S., Arisov, Y., "Selective water sorbent for solid sorption chiller: experimental results and modeling", Int J Refrig 2004; 284:293-27.

[7] Miyazaki T., Akisawa A., Saha B.B., El-Sharkawy I.I., Chakraborty A., "A new cycle time allocation for enhancing the performance of two-bed adsorption chillers", Int $\mathrm{J}$ Refrig 2009; 846:853-32.

[8] El-Sharkawy I.I., AbdelMeguid H., Saha B.B., "Towards an optimal performance of adsorption chillers: Reallocation of adsorption/desorption cycle times", Int J Heat Mass Transfer 2013; 171:182-63.

[9] Goyal P., Baredar P., Mittal A., Siddiqui A.R., "Adsorption refrigeration technology An overview of theory and its solar energy applications", Renew. Sustain. Energy Rev. 2015; 1389:1410-53.

[10] Bataineh K., Taamneh Y., "Review and recent improvements of solar sorption cooling systems", Energy Build. 2016; 22:37-128.

[11] Freni A., Characterization of Zeolite-Based Coatings for Adsorption Heat Pumps, $1^{\text {st }}$. ed., Vol. 1, Springer, Berlin,2015, pp 16-18.

[12] Lior N., Advances in water desalination, $1^{\text {st }}$. ed., Vol. 1, Wiley, New York, 2013, pp. 405-406.

[13] Koronaki I.P., Papoutsis E.G., Papaeftimiou V.D., "Thermodynamic modeling and exergy analysis of a solar adsorption cooling system with cooling tower in Mediterranean conditions", Appl Therm Eng 2016; 1027:1038-99.

[14] Papoutsis E.G., Koronaki I.P., Papaefthimiou V.D., "Numerical simulation and parametric study of different types of solar cooling systems under Mediterranean climatic conditions", Energy Build. 2017; 601:611-138.

[15] Saha B.B., Chakraborty A., Koyama S., Aristov Y.I., "A new generation cooling device employing $\mathrm{CaCl}_{2}$-in-silica gel-water system”, Int J Heat and Mass Transfer 2009; 516:524-52.

[16] The Mathworks. The mathworks. MA: MatLab Natick, http://www.mathworks.com; 2012.

[17] Lemmon, E.W., Huber, M.L., McLinden, M.O., 2011. REFPROP, NIST Standard Reference Database 23, v.8," National Institute of Standards, Gaithersburg, MD, U.S.A.

[18] Jribi S., Saha B.B., Koyama S., Chakraborty A., Ng K.C., "Study on activated carbon/HFO-1234ze(E) based adsorption cooling cycle", Appl Therm Eng 2013; 1570:1575-50. 